\title{
A comparative study of efficacy of antihypertensive drugs and feto-maternal outcome in the treatment of pregnancy induced hypertension
}

\author{
Kavita Babbar $^{1 *}$, Meena Armo ${ }^{1}$, Rajib Lochan Bhanja ${ }^{2}$ \\ ${ }^{1}$ Department of Obstetrics \& Gynaecology, Chhattisgarh institute of medical sciences, Bilaspur, Chhattisgarh, India \\ ${ }^{2}$ Department of Cardiology, Apollo Hospital, Bilaspur, Chhattisgarh, India
}

Received: 09 September 2015

Accepted: 05 October 2015

\author{
*Correspondence: \\ Dr. Kavita Babbar, \\ E-mail: drsonal.babbar@gmail.com
}

Copyright: $(\odot$ the author(s), publisher and licensee Medip Academy. This is an open-access article distributed under the terms of the Creative Commons Attribution Non-Commercial License, which permits unrestricted non-commercial use, distribution, and reproduction in any medium, provided the original work is properly cited.

\begin{abstract}
Background: Hypertensive disorders are the most common medical disorders in pregnancy contributing significantly to maternal and perinatal mortality and morbidity worldwide. The incidence is around 3-10\% of all pregnancies. The aim of antihypertensives is to reduce, stabilize the blood pressure and thus minimize the risks such as placental abruption, maternal cardiac failure, cerebral hemorrhage; but they should not have any adverse effects on the uteroplacental circulation and the fetus. Antihypertensive drugs are often used to lower blood pressure to prevent this progression to adverse outcomes for the mother and the fetus. The risk of developing severe hypertension is reduced to half by using antihypertensive medications. The aim and objectives of the study was a comparative study of the efficacy of methyldopa, nifedipine versus labetalol and the feto- maternal outcome in gestational hypertension in a tertiary care referral centre.

Methods: A prospective study on 240 outpatients as well as inpatients of the antenatal ward of Obstetrics and Gynaecology department of Chhattisgarh Institute of Medical Sciences, Bilaspur which is a tertiary care referral hospital. The patients randomly divided in three groups. The first group received alpha-methyl dopa $250 \mathrm{mg}$ tds, second $20 \mathrm{mg}$ bd nifedipine and the third one labetalol 100 $\mathrm{mg}$ bd. Mean arterial pressure calculated by systolic BP +2 DBP/3.The fall in BP calculated along with time required, dose of drug required, spontaneous/ induced labour or caesarean section, adverse maternal and the fetal outcome was observed.

Results: Maximum number of patients that is $145(60.42 \%)$ patients belonged to the age group of 19 to 24 years and were primigravida (70.42\%) presenting at 33-37 weeks of gestation. Significant fall in MAP was seen in patients receiving nifedipine and labetalol. Mean time to control blood pressure is $46.32 \mathrm{hrs}$ in methyldopa group, 30.44hrs in nifedipine group and $37.24 \mathrm{hrs}$ in labetalol group. 103 (42.9\%) patients had normal delivery whereas 137 (57.1\%) required a caesarian section, higher rate of spontaneous labour in nifedipine and labetalol group. Most common sideeffect observed was headache; the other side effects included drowsiness, more in patients treated with methyldopa, weakness, more in patients treated with labetalol. The fetal outcome was better with labetalol and nifedipine than methyl-dopa group.

Conclusions: The decreased association from maternal and fetal side-effects, the comparatively better hypotensive action indicates that labetalol and nifedipine is suitable for use during pregnancy. Labetalol is safer, quicker in achieving adequate control of blood pressure with considerable prolongation of the duration of pregnancy with fewer side effects on the mother as well as the neonate when used in the management hypertensive disorders of pregnancy.
\end{abstract}

Keywords: Pregnancy, Hypertension, Methyldopa, Nifedipine, Labetalol, Efficacy 


\section{INTRODUCTION}

Hypertension during pregnancy is defined as a blood pressure of $140 / 90 \mathrm{mmHg}$ or greater on two occasions more than 4 hours apart in a previously non-hypertensive person. ${ }^{1}$

Hypertensive disorders in pregnancy remain one of the major causes of maternal and perinatal mortality in developing as well as developed countries. ${ }^{2}$ In some women, it can become more serious resulting in hospital admission due to pre-eclampsia, eclampsia and adverse fetal effects. Antihypertensive drugs are often used to lower blood pressure with the aim of preventing this progression to adverse outcomes for the mother and the fetus.

A wide spectrum of antihypertensive agents represents the key of successful pregnancy hypertension treatment and opportunity of choice, in accordance with indications and availability of drugs provided by drug tendering. The risk of developing severe hypertension is reduced to half by using antihypertensive medications. Methyldopa, labetalol and long-acting nifedipine are acceptable oral antihypertensive agents if drug therapy is required in pregnant women with mild to moderate hypertension. ${ }^{3}$

According to the National High Blood Pressure Education Program Working Group (NHBPEPWG), hypertensive disorders in pregnancy are classified as:

1. Gestational hypertension

2. Pre-eclampsia and eclampsia

3. Pre-eclampsia superimposed on chronic hypertension

4. Chronic hypertension

a. Hypertensive disorders in pregnancy remain one of the major causes of maternal and perinatal mortality in developing as well as developed countries. The commonly used antihypertensive drugs in pregnancy with proven safety are:

5. Alpha-methyldopa

6. Nifedipine (calcium channel blocker)

7. Labetalol

Methyldopa was most commonly used for treatment of hypertension during pregnancy but it takes longer time to act and also less efficacious as hypotensive drug. It is still the most commonly used drug for long term control of blood pressure in pregnancy. Methyldopa is a centrally acting adrenergic antagonist that acts by stimulation of the central alpha 2 receptors, leading to a decrease in sympathetic nerve activity with resultant arterial dilatation and reduction in BP. Methyldopa should not be used if there is a substantial risk of maternal depression when a beta-blocking agent or calcium antagonist may be more suitable.

Nifedipine is a nondihydropyridine calcium channel blocker. Maternal adverse effects with nifedipine include tachycardia, palpitations, peripheral oedema, headaches, and facial flushing. ${ }^{5}$ Rapid acting nifedipine should not be used for treating hypertension or hypertensive emergencies especially in pregnancy because it has been associated with fatal and nonfatal untoward cardiovascular events as well as compromised placental perfusion. ${ }^{6}$

Labetalol gives better control of blood pressure compared to other anti-hypertensive agents. Labetalol is a combined alpha- and beta-blocker and has the advantage over other beta blockers due to its additional arteriolar vasodilator action that helps to lower peripheral vascular resistance with little or no decrease in cardiac output. ${ }^{4}$

Today, though oral medications are available and widely used for the treatment of PIH, the physicians still have to deal with many challenges. Antihypertensive drugs are often used to lower blood pressure with the aim of preventing its progression to adverse outcomes for the mother and the fetus. A wide spectrum of antihypertensive agents represents the key of successful pregnancy hypertension treatment and opportunity of choice, in accordance with indications and availability of drugs provided by drug tendering. ${ }^{5-7}$

In this backdrop, a study was designed to compare the antihypertensive drugs - methyldopa, nifedipine versus labetalol versus in pregnancy induced hypertension (PIH) in tertiary care referral institute.

The objectives of the study was to evaluate the efficacy of methyldopa, nifedipine versus labetalol in controlling blood pressure in pregnancy and to study the maternal and fetal outcome after these drugs administration in pregnancy.

\section{METHODS}

A prospective randomized study was carried out in 240 pregnant women from 2011-2014 in the Department of Obstetrics and Gynaecology, Chhattisgarh Institute of Medical Sciences Bilaspur. All pregnant women attending the antenatal clinic were screened for and hypertensive pregnant women were included in the study after obtaining informed consent. The study was approved by the institutional ethics committee of the hospital.

\section{Inclusion criteria}

The criteria for diagnosis and classification of the hypertensive disorder of pregnancy will be obtained according to the NHBPEPWG. Medical and obstetric history taking and physical examination were performed at the time of initial recruitment. Pregnant patients diagnosed with systolic blood pressure of $\geq 140 \mathrm{mmHg}$ and a diastolic blood pressure of $\geq 90 \mathrm{mmHg}$ requiring medication and gestational age between more than 20 weeks of pregnancy (calculated from the first day of last 
menstrual period) were included in the study excluding oedema or proteinuria. Only singleton pregnancy with vertex presentation was included.

\section{Exclusion criteria}

Patients suffering from bronchial asthma, any preexisting cardiovascular disorder, diabetes, $\mathrm{Rh}$ isoimmunisation, patients at risk of major obstetric complications - antepartum haemorrhage, malnutrition, multifetal gestation and hydramnios during the current pregnancy and patients who had already received antihypertensive drugs were excluded.

Patients (80 each) were randomised to each of the three treatment arms - methyldopa, nifedipine and labetalol, with bed rest for patients. After randomization, first group received methyldopa $250 \mathrm{mg}$ t.i.d, second received nifedipine $10 \mathrm{mg}$ b.d. and labetalol $100 \mathrm{mg}$ b.d. Mean Arterial pressure (MAP) was calculated according to formula systolic $\mathrm{BP}+2$ diastolic $\mathrm{BP} / 3$. Patients were subjected to 6 hourly BP monitoring. Comparison of the drugs was done daily by calculating MAP of these groups. If there was no control in BP even after $48 \mathrm{hrs}$ of drug therapy, dose of the drug was doubled. Response in lowering BP was assessed over a period of 7 days. Observations were made as regards fall in BP, time required to control $\mathrm{BP}$, average dose of drugs required to control BP, onset of labour-spontaneous/induced or caesarean section, adverse effects of drugs and fetal outcome.

Measurement of blood pressure (BP) was done using mercury sphygmomanometer (auscultation method) taken after 15 minutes of rest. Readings were taken at least on two occasions six hours apart before diagnosing the patient as hypertensive. The patient was made to lie in the left lateral position with the right arm well supported at the level of the heart. Systolic BP corresponded to appearance of the first tapping sounds and diastolic BP was recorded at the point where the sounds first became muffled. (Korotkoff phase IV). Patients were followed up and $\mathrm{BP}$, pulse rate and fetal heart rate were recorded every 15 minutes for two hours after initiation of treatment. Patients were advised to take the minimum dose of drug which kept the BP below $90 \mathrm{mmHg}$, with advice to come for weekly follow up and get admitted if BP rose beyond the point of control. Patients who remained uncontrolled in spite of therapy in these groups were closely monitored in the hospital and attempt was made to continue the pregnancy up to 37 completed weeks followed by induction of labour and caesarean section, wherever induction was contraindicated or failed.

\section{RESULTS}

According to Table 1, among the total 240 patients, maximum number of patients that is $145(60.42 \%)$ patients belonged to the age group of 19 to 24 years: 51 patients (63.75\%) in Group 1 and 49 patients $(61.25 \%)$ in Group 2 and 45(56.25\%) patients in Group 3.

Table 1: Age-wise case distribution.

\begin{tabular}{|llll|} 
& Methyldopa & Nifedipine & Labetalol \\
\hline$\leq 18 \mathrm{yr}$ & $5(6.25 \%)$ & $7(8.75 \%)$ & $6(7.5 \%)$ \\
\hline $19-24 \mathrm{yr}$ & $51(63.75 \%)$ & $49(61.25 \%)$ & $45(56.25 \%)$ \\
\hline $25-30 \mathrm{yr}$ & $17(21.25 \%)$ & $20(25.0 \%)$ & $18(22.5 \%)$ \\
\hline$>30 \mathrm{yr}$ & $7(8.75 \%)$ & $4(5.0 \%)$ & $11(13.75 \%)$ \\
\hline
\end{tabular}

Table 2 states that in the present study, 169(70.4\%) patients were primigravidae, 56 patients $(70.0 \%)$ in methyldopa group, 52(65.0\%) in nifedipine and 61 patients $(76.25 \%)$ in labetalol group.

Table 2: Parity distribution of the cases.

\begin{tabular}{|llll|}
\hline Parity & Methyl-dopa & Nifedipine & Labetalol \\
\hline \multirow{2}{*}{ Primigravida } & 56 & 52 & 61 \\
& $(70.0 \%)$ & $(65.0 \%)$ & $(76.25 \%)$ \\
\hline \multirow{2}{*}{ Multigravida } & 24 & 28 & 19 \\
& $(30.0 \%)$ & $(35.0 \%)$ & $(23.75 \%)$ \\
\hline
\end{tabular}

In the study 49 patients $(61.25 \%)$ in group 1,57 patients $(71.25 \%)$ in group 2 and 55 patients $(68.75 \%)$ in group 3 presented at 33-37 weeks gestational age (Table 3).

Table 3: Gestational age at the time of presentation.

\begin{tabular}{|llll|}
\hline $\begin{array}{l}\text { Gestational } \\
\text { age (wks) }\end{array}$ & Methyldopa & Nifedipine & Labetalol \\
\hline $21-24$ & $4(5.0 \%)$ & $5(6.25 \%)$ & $6(7.5 \%)$ \\
\hline $25-28$ & $2(2.5 \%)$ & $2(2.5 \%)$ & $3(3.75 \%)$ \\
\hline $29-32$ & $17(21.25 \%)$ & $16(20.0 \%)$ & $18(22.5 \%)$ \\
\hline $33-37$ & $49(61.25 \%)$ & $57(71.25 \%)$ & $55(68.7 \%)$ \\
\hline
\end{tabular}

Table 4: Dose of methyl dopa at which control of BP achieved.

\begin{tabular}{|lll|}
\hline Dose (mg/day) & Frequency & Percentage \\
\hline 750 & 37 & 46.25 \\
\hline 1000 & 19 & 23.75 \\
\hline 1500 & 16 & 20 \\
\hline 2000 & 8 & 10 \\
\hline
\end{tabular}

Table 5: Dose of labetalol at which control of BP achieved.

\begin{tabular}{|lll|}
\hline Dose (mg/day) & Frequency & Percentage \\
\hline 200 & 16 & 20 \\
\hline 300 & 14 & 17.5 \\
\hline 400 & 39 & 48.75 \\
\hline 600 & 11 & 13.75 \\
\hline
\end{tabular}

Figure 1 shows comparison of MAP in both the groups at Day 1 and Day 8. In the present study, the mean arterial pressure on admission in patients treated with 
methyldopa, nifedipine and labetalol was $109.72 \mathrm{mmHg}$, $109.92 \mathrm{mmHg}, 109.56 \mathrm{mmHg}$, and while on day 8 it reduced to $98.2 \mathrm{mmHg}, 94.8 \mathrm{mmHg}$, and $96.4 \mathrm{mmHg}$ respectively.

Table 6: Dose of nifedipine at which control of BP achieved.

\begin{tabular}{|lll|}
\hline Dose (mg/day) & Frequency & Percentage \\
\hline 20 & 9 & 11.25 \\
\hline 30 & 17 & 21.25 \\
\hline 40 & 34 & 42.5 \\
\hline 60 & 20 & 25 \\
\hline
\end{tabular}

The average time to control blood pressure is $46.32 \mathrm{hrs}$ in methyldopa group, $30.44 \mathrm{hrs}$ in nifedipine group and $37.24 \mathrm{hrs}$ in labetalol group (Figure 2). The dose of methyldopa to control blood pressure is $750 \mathrm{mg} /$ day in 37 patients $(46.25 \%), 40 \mathrm{mg} /$ day in 28 patients $(42.5 \%)$ by nifedipine and $400 \mathrm{mg} /$ day in 39 patients $(48.75 \%)$ by labetalol (Table 4, 5, 6).

\section{Response after drug administration}

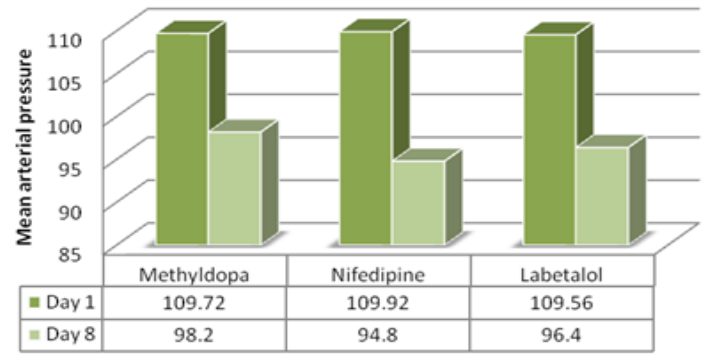

Figure 1: Reduction in BP after drug administration.

In the present study Figure 3 shows $103(42.9 \%)$ patients had normal delivery whereas $137(57.1 \%)$ required a caesarian section. 9 patients in group 1 went in spontaneous labour while 14 patients were induced in group 2, 20 patients went in spontaneous labour and 23 patients were induced and in group 3, 17 patients went in spontaneous labour and 20 patients were induced (Figure 4). Thus the rate of spontaneous labour was more in patients treated with nifedipine and labetalol. This may be accounted to the fact that labetalol has ripening effect on the cervix. The commonest adverse effects noted were tachycardia (4-11\%), occipital headache (3-9\%), postural hypotension (3-8\%) and depression (2-7\%). Tachycardia $(11.25 \%)$ and occipital headache $(8.75 \%)$ were more common with nifedipine compared to methyldopa and labetalol groups. Postural hypotension (7.5\%), drowsiness $(8.75 \%)$ and depression $(8.75 \%)$ were more commonly reported side effects with methyldopa group compared to nifedipine and labetalol but weakness (5\%) more in patients treated with labetalol. The incidence of side-effects such as nausea, vomiting, myalgia was similar in the three groups.

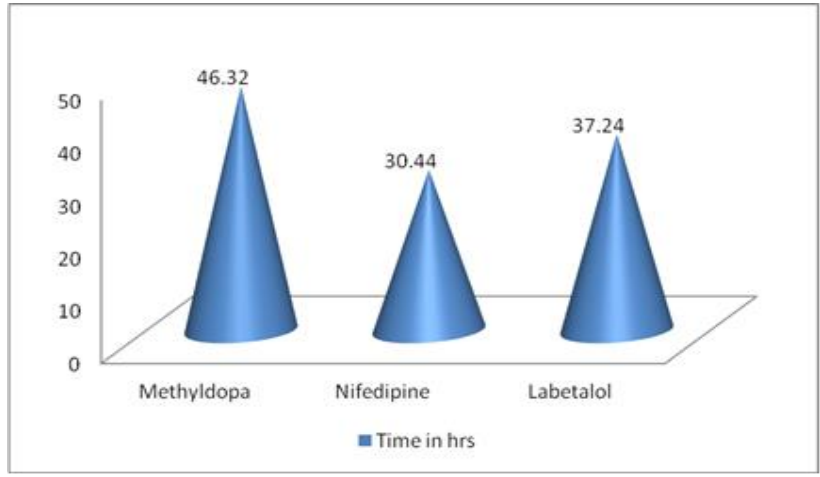

Figure 2: Mean time to achieve control of blood pressure.

The fetal outcome revealed not much difference in the three treatment arms as correlated with other similar studies.

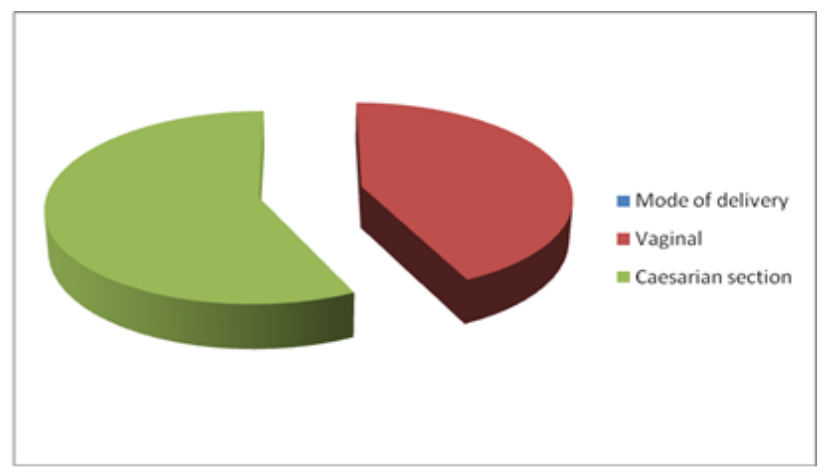

Figure 3: Maternal obstetric outcome ( $\mathrm{N}=\mathbf{2 4 0})$.

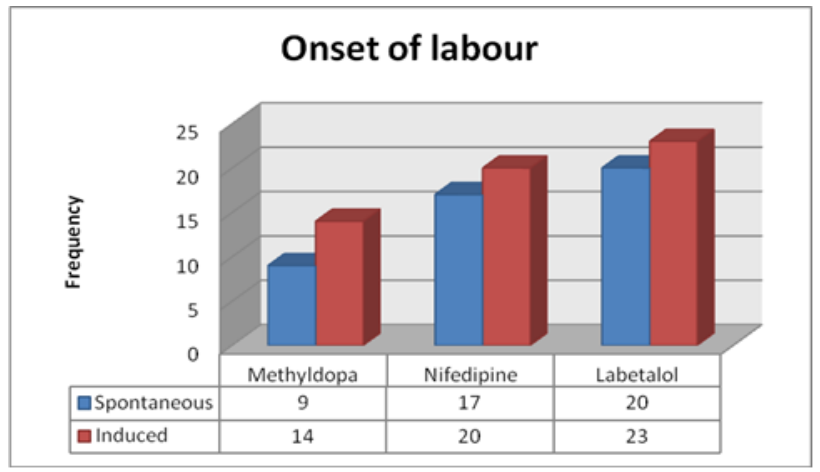

Figure 4: Onset of labour in normal delivery $(\mathrm{N}=103)$.

\section{DISCUSSION}

The primary objective of management in women with pregnancy-induced hypertension is to protect the safety of the mother and the fetus and the subsequent delivery of a healthy baby. Age distribution shows maximum patients between $19-24$ years in three groups $(63.75 \%$ in methyldopa group, $61.25 \%$ in nifedipine and $57.77 \%$ in labetalol group) and there was no significant difference in age distribution in the groups. Majority of the pregnant women presenting to our health facility are illiterate with 
only rudimentary medical knowledge of their own pregnancies with majority had no prior antenatal checkup . Age has an important influence on the incidence of hypertensive disorders of pregnancy. Young primigravidae under 20 years and all patients over 30 years have an increased chance of hypertension. ${ }^{9}$

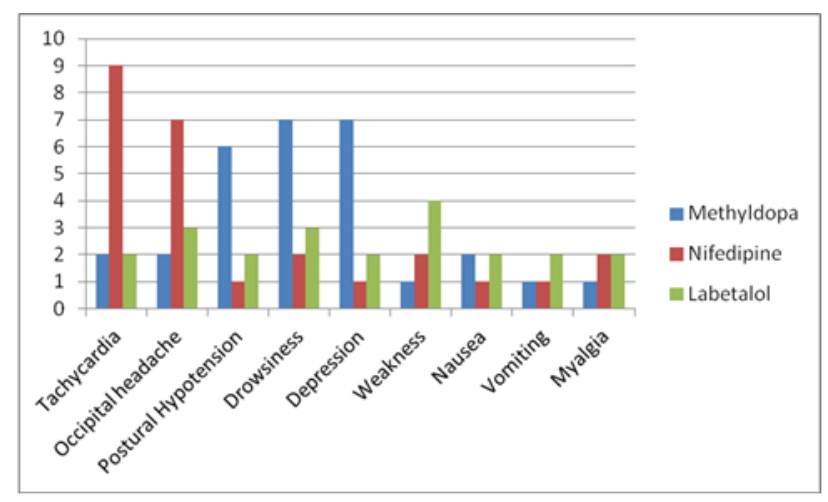

Figure 5: Adverse effects of the drugs.

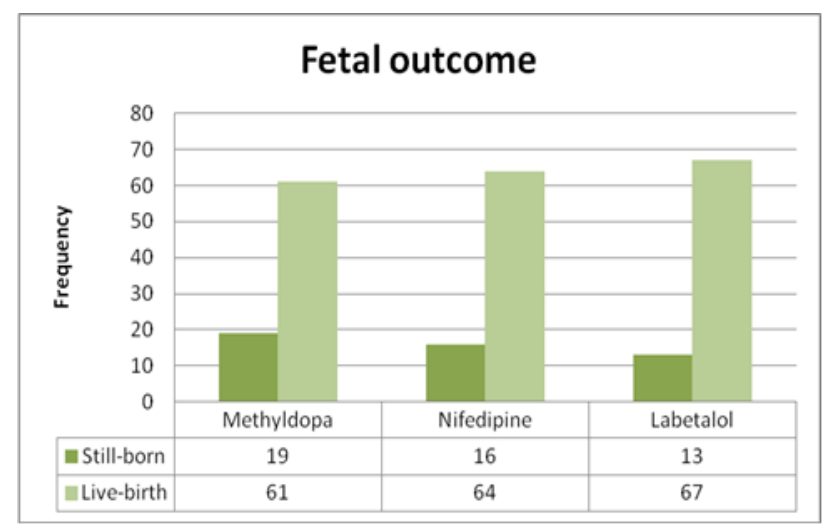

Figure 6: Fetal outcome.

Parity distribution shows maximum patients of PIH with G1P0 (primigravidae) in both groups $(70 \%$ in methyldopa group, $65 \%$ in nifedipine and $76.25 \%$ in labetalol this finding is similar to previous studies. (Redman CWG et al, Plouin PF et al). ${ }^{10,11}$ Preeclampsia is primarily regarded as a disease of first pregnancy. Several other authors have reported primiparity in 52$73 \%$ patients of preeclampsia. ${ }^{12}$

Most patients with PIH $61.25 \%$ in methyldopa group, $71.25 \%$ in nifedipine group and $68.75 \%$ in labetalol group belonged to 33-37 weeks gestational age. This finding of the most common gestational age at which $\mathrm{PIH}$ developed is supported by other studies as Lardoux $\mathrm{H}$ et al. ${ }^{10,13}$ However, according to another observation, the majority of cases of mild gestational hypertension develop at or beyond 37 weeks gestation. (Sibai BM). The incidence of PIH is distributed unevenly throughout late gestation, increasing with advancing gestation (Sibai $\mathrm{BM}) .{ }^{14}$
Approximately half of PIH cases occur at term $(\geq 37$ weeks' gestation), including most cases of gestational hypertension. The mean gestational age at presentation was 32.7 weeks which is comparable with other study (i.e. 37 weeks). ${ }^{15}$

In the present study, the mean arterial pressure in patients treated with methyldopa on admission was $109.72 \mathrm{mmHg}$, while on day 8 it reduced to $98.2 \mathrm{mmHg}$, with nifedipine the mean arterial pressure on admission was 109.92 $\mathrm{mmHg}$ which reduced to $94.68 \mathrm{mmHg}$ on day 8 and with labetalol, the mean arterial pressure on admission was $109.56 \mathrm{mmHg}$ which reduced to $96.4 \mathrm{mmHg}$ on day 8 . On comparing these drugs, MAP on admission was comparable but on day 8 , significant fall in MAP was seen in patients receiving labetalol and nifedipine. The comparable effect of methyldopa, nifedipine and labetalol on BP control in hypertensive disorders of pregnancy is supported by previous studies. (Pickles CJ et al, Sibai $\mathrm{BM}$ et al). ${ }^{16,17}$ However, one study says that labetalol provides more efficient control of BP than methyldopa in the treatment of mild hypertension in pregnancy and had a significant fall in MAP as against $68.5 \%$ in patients taking methyldopa. ${ }^{6}$

In the present study, the mean time required to control BP in group 1 was 46.32 hours, in group 2 it was 30.44 hours and in group 3 it took 37.24 hours. The difference between the groups was with nifedipine and labetalol showing earlier control of BP than methyldopa.

The dose of methyldopa to control blood pressure is $750 \mathrm{mg} /$ day in 37 patients $(46.25 \%), 40 \mathrm{mg} /$ day in 34 patients $(42.5 \%)$ by nifedipine and $400 \mathrm{mg} /$ day in 39 patients $(48.75 \%)$ by labetalol. Lardoux et al found that the average daily dose of labetalol required for satisfactory blood pressure control was $600 \mathrm{mg} .{ }^{13}$

9 patients in group 1 went in spontaneous labour while 14 patients were induced in group 2, 17 patients went in spontaneous labour and 20 patients were induced and in group 3, 20 patients went in spontaneous labour and 23 patients were induced. The rate of spontaneous labour was more in patients treated with labetalol. This may be accounted to the fact that labetalol has ripening effect on the cervix. Lamming et al too reported a higher incidence of spontaneous labour in the labetalol group. ${ }^{9}$

The commonest adverse effects noted were occipital headache (3-9\%), postural hypotension (3-8\%), tachycardia (4-11\%), and depression (2-7\%). Tachycardia $(11 \%)$ and occipital headache $(9 \%)$ were more common with nifedipine compared to methyldopa and labetalol groups. Postural hypotension drowsiness and depression were more commonly reported side effects with methyldopa group (8\%) compared to nifedipine and labetalol but weakness more in patients treated with labetalol. The incidence of side-effects such as nausea, vomiting, myalgia was similar in the three groups. Study conducted by Verma et al. states that adverse events 
observed were lower in the labetalol treated group compared to the methyldopa group. ${ }^{19}$ In another study patients receiving methyldopa complained of side-effects such as drowsiness $(22.2 \%)$, headache (14.8\%), nasal congestion $(7.4 \%)$, and postural hypotension $(5.6 \%)$.

The effect on fetal and maternal outcomes like the incidence of prematurity, intrauterine growth retardation, perinatal death, need for NICU, incidence of eclampsia and incidence of elective or caesarean section in the mother must be considered before pronouncing that labetalol may be preferred in PIH on account of equal efficacy and better tolerability

The fetal outcome revealed that there was not a major difference due to the choice of antihypertensive. Unlike other antihypertensive drugs labetalol reduces peripheral resistance without significantly reducing maternal cardiac output and pulse rate. This may be an additional factor in maintaining adequate placental perfusion and therefore foetal oxygenation in the treatment of pregnancy hypertension with labetalol. Drug treatment of mild chronic or pregnancy-induced hypertension improves maternal outcomes but does not clearly improve perinatal outcomes. $^{20}$

All forms of antihypertensive therapy were associated with a higher risk for SGA, preterm birth and admission to the NICU, and multiple therapies had the strongest association with this events. $^{21}$

\section{CONCLUSIONS}

Treating the hypertension does not alter the progression of disease but early treatment decreases not only the frequency of hypertensive crisis, but also the rate of neonatal complications. Antihypertensive medications are mainly used to prevent or treat severe hypertension, to prolong pregnancy for as long as safely possible thereby maximizing the gestational age of the infant, and to minimize fetal exposure to medications that may have adverse effects.

This study confirms the previous findings that labetalol is an effective and safe drug for use in the control of blood pressure in pregnancy-induced hypertension. The low incidence of maternal and foetal side-effects together with the excellent perinatal outcome in a condition usually accompanied by a high maternal and foetal mortality and morbidity confirms its suitability for use during pregnancy. Nifedipine is equally efficacious and better tolerated compared to methyldopa in the treatment of new onset hypertension during pregnancy. However, the effect on fetal and maternal outcomes must be considered before selecting any drug in the treatment of hypertensive disorders of pregnancy.

Awareness regarding PIH and availability of easily accessible and affordable health care services to rural population and poor people is important which shall be helpful in reducing the $\mathrm{PIH}$ related morbidity and mortality.

\section{ACKNOWLEDGEMENTS}

We sincerely thank Lt. Col. (Prof.) Dr S. K. Mohanty, Dean and Prof. Dr R. Murthy, Medical superintendent CIMS, for granting permission. We also thank all interns for collecting the records.

\section{Funding: No funding sources}

Conflict of interest: None declared

Ethical approval: The study was approved by the Institutional Ethics Committee

\section{REFERENCES}

1. Davey DA, MacGillivray I. The classification and definition of the hypertensive disorders of pregnancy. Am J Obstet Gynecol. 1988;158(4):8928.

2. Magee LA, Von Dadelszen P. Treatment of hypertension in pregnancy. Can J Clin Pharmacol. 2004;11(2):e199-e201.

3. Abalos E, Duley L, Steyn DW, Henderson-Smart DJ. Antihypertensive drug therapy for mild to moderate hypertension during pregnancy. Cochrane Database Syst Rev. 2007;(1):CD002252.

4. Magee LA, Ornstein MP. Management of hypertension in pregnancy. BMJ. 1999;318(7194):1332-6.

5. Giannubilo SR, Bezzeccheri V, Cecchi S, Landi B, Battistoni GI. Nifedipine versus labetalol in the treatment of hypertensive disorders of pregnancy. Arch Gynecol Obstet. 2012;286:637-42.

6. El-Qarmalawi AM, Morsy AH, al-Fadly A, Obeid A, Hashem M. Labetalol vs. methyldopa in the treatment of pregnancy-induced hypertension. Int $\mathbf{J}$ Gynaecol Obstet. 1995;49:125-30.

7. Khedun SM, Moodley J, Naicker T, Maharaj B .Drug management of hypertensive disorders of pregnancy. Pharmacol Ther. 1997;74: 221-58.

8. Guzick DS, Klein VR, Tyson JE, Lasky RE, Gant NF, Rosenfeld CR. Risk factors for the occurrence of pregnancy induced hypertension. Informa healthcare - Hypertension in pregnancy. 1987;b6(2):281-97 .

9. Zibaeenazhad MJ, M Ghodsi P Arab, Gholzom N. the prevalence of hypertensive disorders of pregnancy in Shiraz, Southern Iran; Iranian Cardiovascular Research Journal. 2010;4:169-72.

10. Redman CWG, Gallery ED, Mitchell MD. Fall in BP in response to volume expansion in pregnancy associated hypertension (PE): Why does it occur? BMJ. 1984;2(2):177-82.

11. Plouin PF, Breart G, Maillard F, Papiernik E, Relier JP. Comparison of antihypertensive efficacy and perinatal safety of labetalol and methyldopa in the treatment of hypertension in pregnancy: a randomized controlled trial. Br J Obstet Gynaecol. 1988;95:868-76 . 
12. Sajith M. Incidence of pregnancy induced hypertension and prescription pattern of antihypertensive drugs in pregnancy International Journal of Pharma Sciences and Research. 2014;(4):168-72.

13. Lardoux H, Blazquez G, Leperlier E, Gérard J. Randomized, comparative study on the treatment of moderate arterial hypertension during pregnancy: methyldopa, acebutolol, labetalol. Arch Mal Coeur Vaiss. 1988;81:137-40.

14. Sibai BM. Diagnosis and management of gestational hypertension and pre-eclampsia. Obstet Gynecol. 2003;102(1):181-92.

15. Zhang J, Zeisler J, Hatch MC, Berkowitz G. Epidemiology of pregnancy-induced hypertension. Epidemiology Revised. 1997;19:218-32.

16. Pickles CJ, Broughton Pipkin F, Symonds EM. A randomised placebo controlled trial of labetalol in the treatment of mild to moderate pregnancy induced hypertension. $\mathrm{Br} \quad \mathrm{J}$ Obstet Gynaecol. 1992;99(12):964-8 .

17. Sibai BM, Mabie WC, Shamsa F, Villar MA, Anderson GD. A comparison of no medication versus methyldopa or labetalol in chronic hypertension during pregnancy. Pharmacology J Obstet Gynecol. 1990;162(4):960-6.

18. Lamming GD. Symonds SM. Use of labetalol and methyldopa in pregnancy-induced hypertension .Br. J. clin. Pharmac. 1979;8:217S-22S.

19. Verma R, Lahon K, Tonpay SD, Joshi Kale V, Jain DK. A comparative randomized controlled parallel group study of efficacy and tolerability of labetalol versus methyldopa in the treatment of new onset hypertension during pregnancy. Pharmacology. 2012;2:23-31.

20. Magee LA, Ornstein MP, von Dadelszen P. Management of hypertension in pregnancy. BMJ. 1999;318:1332-6.

21. Ray JG, Elizabeth AB. Use of antihypertensive medications in pregnancy and the risk of adverse perinatal outcomes. BMC Pregnancy Childbirth. 2001;1:1-6.

Cite this article as: Babbar $\mathrm{K}$, Armo M, Bhanja RB. A comparative study of efficacy of antihypertensive drugs and feto-maternal outcome in the treatment of pregnancy-induced hypertension. Int J Reprod Contracept Obstet Gynecol 2015;4:1846-52. 